\title{
Design and Implementation of a Lead-Acid Battery Emulator
}

\author{
Andrés Ignacio Santos León, Álvaro Andrés Peña Acosta, Cesar Leonardo Trujillo Rodríguez \& \\ Francisco Santamaría Piedrahita.
}

Grupo de Investigación en Sistemas Eléctricos y Eficiencia Energética - GISE3-UD, Facultad de Ingeniería, Universidad Distrital Francisco José de Caldas, Bogotá D.C., Colombia.

Received 18 September 2019; Accepted 17 March 2020

\begin{abstract}
The lead-acid batteries are a widely spread energy storage technology due to their low cost and good reliability. For most of the applications using battery-based energy storage systems, it is important to assess the battery performance and dynamic behavior. However, the laboratory research on actual batteries is time consuming, costly and may lead to wrong results due to battery capacity attenuation, aging and environmental conditions. These reasons make battery emulation an attractive alternative to reduce the mentioned difficulties. Therefore, in this paper the design and implementation of a leadacid battery emulator are presented. The proposed battery emulator is based on a Flyback converter, the control schemes and battery model were implemented using a Texas Instruments TMS320F28335 DSP. Design considerations of the proposed emulator are discussed and key experimental results about the battery emulator confirm the system feasibility. Finally, main conclusions are presented.
\end{abstract}

Keywords: Battery model, flyback converter, lead-acid battery emulator.

\section{Introduction}

Rechargeable batteries are electrochemical devices capable of producing an electrical current from a reversible electrochemical reaction. These devices are widely used in electrical and electronics applications as a mean of energy sourcing and storage. In particular, lead-acid batteries are a widely spread technology in distributed generation schemes, uninterrupted power supplies, flexible AC transmission systems, lighting and ignition applications, amongst others, due to its high energy density, tolerance to overcharge and deep discharge, capability of delivering large currents and low cost, the latter being critical in the determination of the overall application cost.

The proper design and operation of these systems rely on a battery model [1]-[4] capable of describing the dynamic behaviour of the battery [1]. Modeling and simulation-based methods are becoming increasingly popular in the analysis of battery-based systems. For instance Collet et al. [5] created a battery emulator based on individual cells that allow representing the current-voltage characteristics of the battery stack. Baumhofer et al. [6] designed a sealed lead-acid (SLA) battery emulator based on a bi-directional high power DC/DC converter, which was capable of sourcing and storing energy in two backup batteries attached to the low voltage side of the converter. Park et al. [7] proposed a programmable power source based on the PIC16F877, called B\# that is capable of reproducing a lithium-ion dynamic current-voltage characteristic. B\# is based on dual-foil, an electrochemical battery model developed by Doyle et al. [8] that solves partial differential equations to compute the terminal voltage, state of charge and temperature of the battery.

\section{E-mail address: cltrujillo@udistrital.edu.co}

ISSN: $1791-2377$ @ 2020 School of Science, IHU. All rights reserved.

doi:10.25103/iestr.133.19
In [9]-[13] the authors review the energy storage technologies for different applications as well as strategies to manage energy in battery-based systems. They also discuss the use of battery-based systems as means of energy sourcing to extend the grid stability. In [14]-[16] some battery models for different battery electro-chemistries are reviewed based on various criteria, such as their ability to model non-linear effects of batteries and the change in the battery due to environmental changes. Shekoofa et al. [17] presented the design and implementation of a lead-acid battery emulator, which is capable of reproducing the dynamic voltage and current characteristics of a lead-acid battery. The emulator is based on a flyback converter topology, and the model equations and control algorithms were implemented using a Texas Instruments TMS320F28335 DSP.

This paper is organized as follows: In section 2 a brief explanation about the determination of battery model parameters and model validation is presented. Section 3 presents the design considerations corresponding to the power stage of the emulator for both, charge and discharge. Section 4 presents the experimental results achieved with the proposed emulator. The last section presents the obtained conclusions.

\section{Battery model parameters}

The determination of the model parameters was done based on the battery model proposed by Tremblay et al. [1], [4]. This model consists of a controlled voltage source in series with a constant resistor. The controlled voltage source represents the inner battery voltage that, in lead-acid batteries, is closely related to the State of Charge - SOC; a non-linear term called the polarisation constant is introduced in the model to represent the non-linear voltage drop when current is extracted from the battery [4]. 
The model accurately represents the dynamic behavior of the battery; however, it does not allow modeling the variation of the battery capacity with respect to the current amplitude. Self-discharge and temperature effects are not taken into account either [1], [4]. The model parameter estimation is well documented in the work presented in [4]. For a lead-acid battery, all of the model parameters can be extracted from the typical constant current discharge given in the battery datasheet or by means of experimental data. In this work the former was used. Five parameters were obtained from the constant current discharge curve: The full charge open-circuit voltage $\left(E_{f}\right)$, the charge $\left(Q_{\text {exp }}\right)$ and voltage $\left(E_{\text {exp }}\right)$ at the end of the exponential zone and the charge $\left(Q_{n o m}\right)$ and voltage $\left(E_{\text {nom }}\right)$ at the end of the nominal zone. These parameters are presented in Tab. 1.

Table 1. Battery parameters extracted from the constant current discharge data

\begin{tabular}{c|c}
\hline Parameter & Value \\
\hline$E_{f}(V)$ & 13.5 \\
$E_{\text {exp }}(V)$ & 0.068049 \\
$Q_{\text {exp }}(A h)$ & 0.94956 \\
$E_{\text {nom }}(V)$ & 100 \\
$Q_{\text {nom }}(A h)$ & 3.15 \\
\hline
\end{tabular}

The main equation governing the terminal voltage of the battery model is given by Eq. Error! Reference source not found.

$$
V_{b a t t}=E_{0}-R i-K \frac{Q}{Q-i t}\left[i t+i^{*}\right]+A e^{-B i t}
$$

Where $E_{0}$ is a constant voltage given by:

$$
E_{0}=E_{f}+K+R i-A
$$

Also

$$
A=E_{f}-E_{\text {exp }}
$$

$R_{i}$ is the internal resistance of the battery; the parameters $A$ and $B$ represent the amplitude and time constant of the exponential, respectively. The parameter $K$ is the polarisation constant given by:

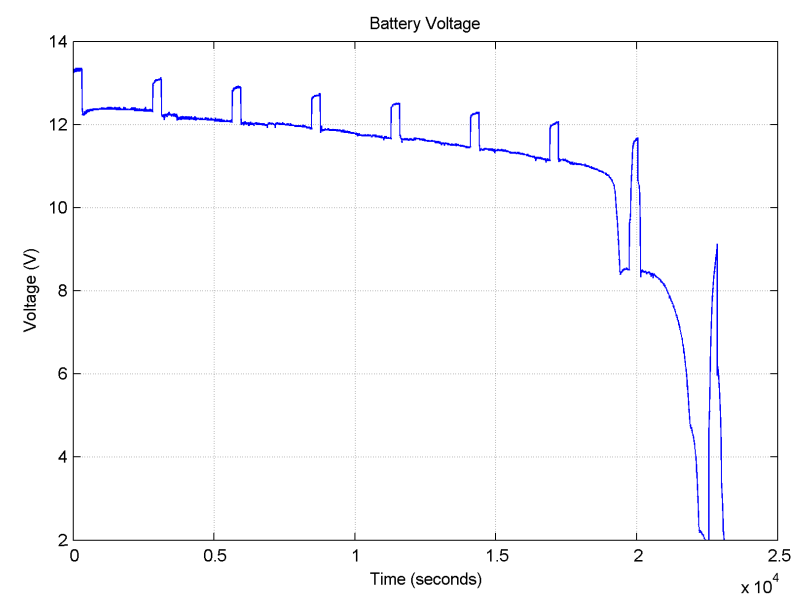

$K=\frac{E_{f}-E_{\text {nom }}+A\left(e^{\left.-B Q_{n o m}-1\right)\left(Q-Q_{\text {nom }}\right)}\right.}{Q_{\text {nom }}}$

Finally, the term $i^{*}$ represents the low-frequency component of the output or input current of the battery. In this study, a CSB GP1272 12 V - 7.2 Ah sealed lead-acid battery was used. Tab. 2 summarizes the model parameters obtained for this battery.

Table 2. Model parameters for the battery understudy

\begin{tabular}{c|c}
\hline Model Parameter & Value \\
\hline$E_{0}(V)$ & 12.5826 \\
$R_{i}(\Omega)$ & 0.023 \\
$K(\Omega / A h)$ & 0.068049 \\
$A(V)$ & 0.94956 \\
$B(A h)^{-1}$ & 100 \\
\hline
\end{tabular}

To verify that the model accurately reproduces the battery behavior, a pulsed current discharge was carried out in the battery under study using standard laboratory equipment, the same pulsed discharge was simulated using MATLAB/Simulink in the battery module from the Simpower Systems library with the aforementioned parameters. Fig. 1 depicts the Simulink setup.

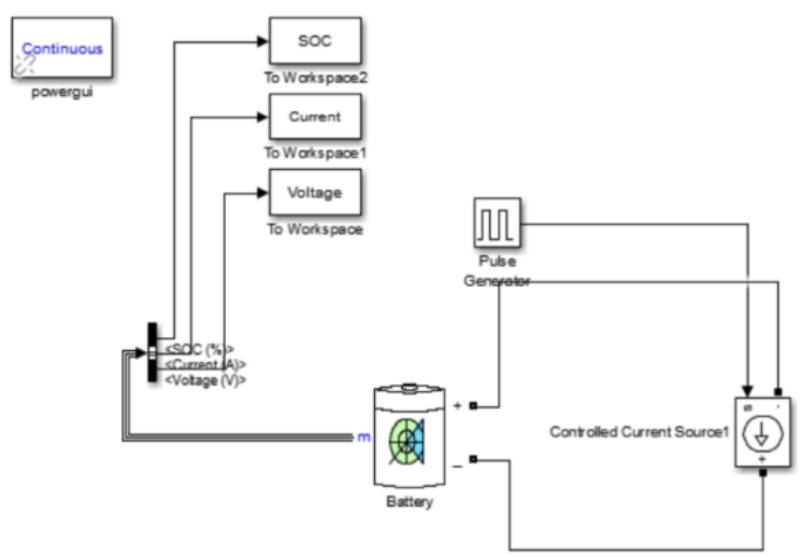

Fig. 1. Simulink Set-Up for pulsed discharge test simulation

The pulsed discharge was adjusted so that every pulse of current extracts about $10 \%$ of the nominal battery capacity, the voltages obtained from both lab test and simulation, are presented in Figures 2 to 4.

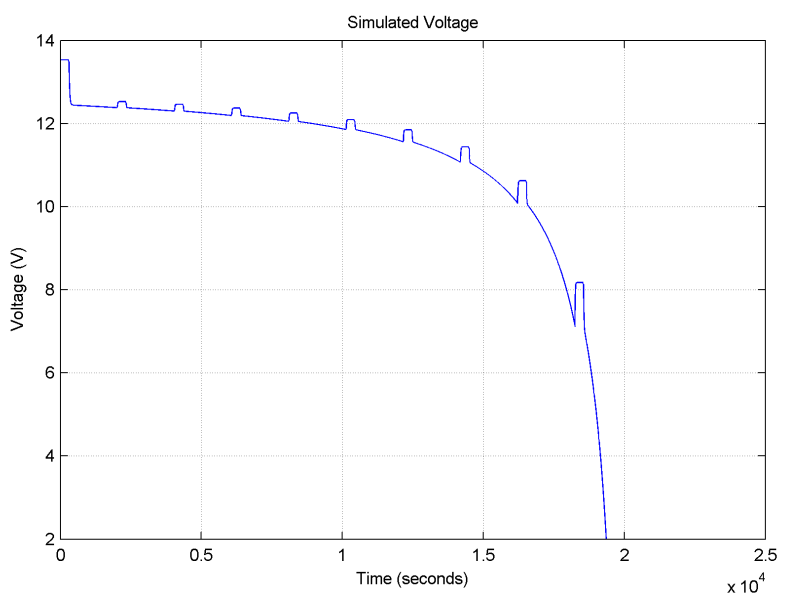

Fig. 2. Real battery voltage response under pulsed discharge at $1.5 \mathrm{~A}$ (Left). Simulated battery voltage (Right) 

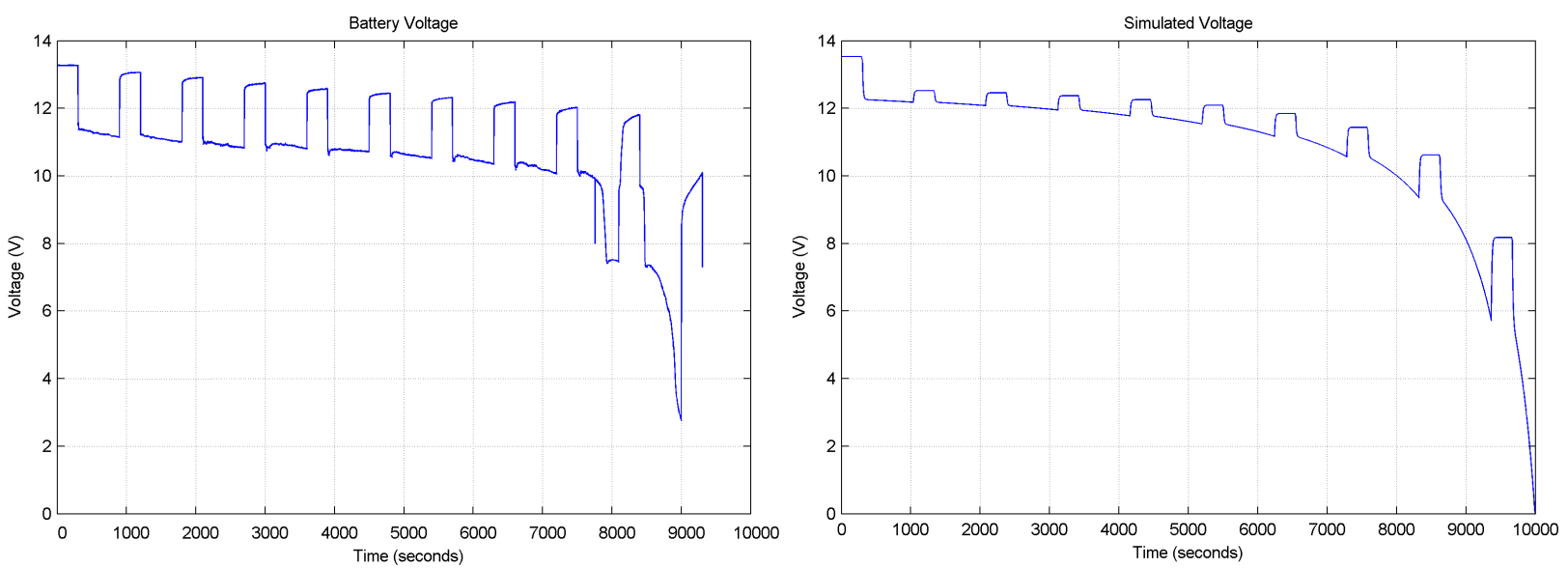

Fig. 3. Real battery voltage response under pulsed discharge at $3 \mathrm{~A}$ (Left). Simulated battery voltage (Right)
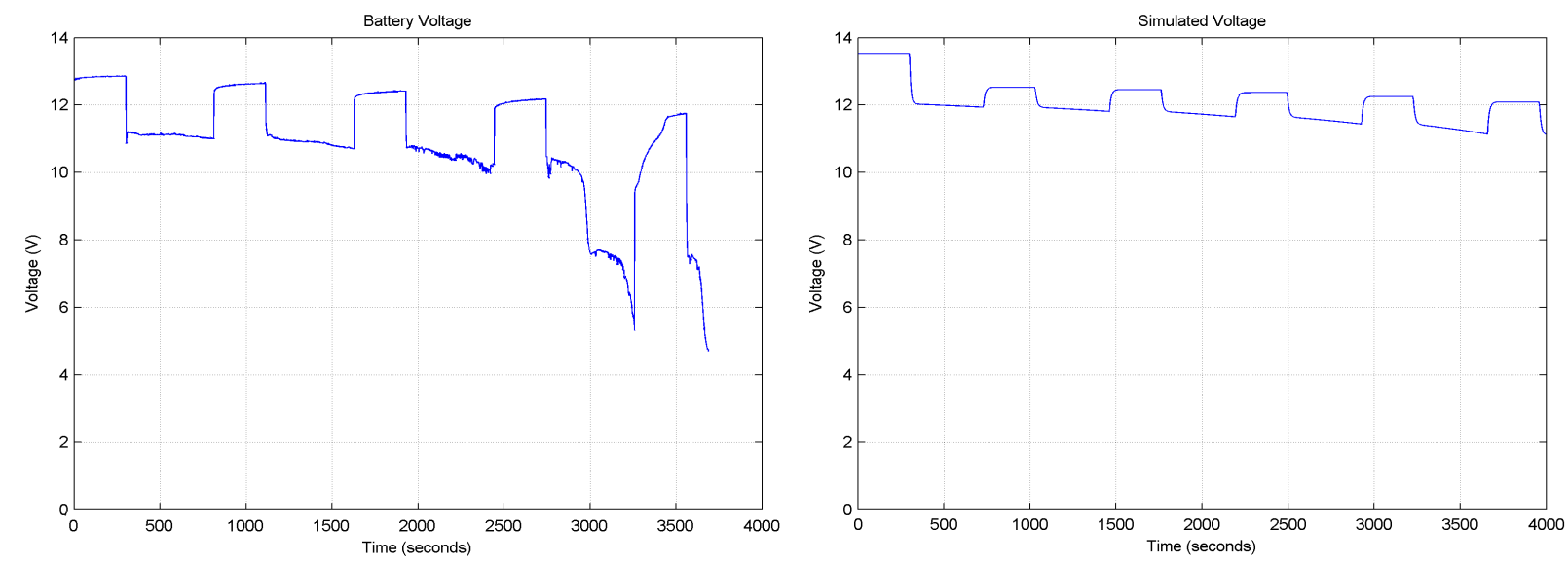

Fig. 4. Real battery voltage response under pulsed discharge at 6 A (Left). Simulated battery voltage (Right)

It can be seen that the voltage from the battery model and the real battery are very similar, a maximum difference of $1 \mathrm{~V}$ between the battery voltage and the simulation was found, mainly in the transitions from load to open circuit, which is attributed to the model limitations mentioned above. The battery model reaches a terminal voltage of $0 \mathrm{~V}$, a behavior that never is observed on the battery understudy, even at very low SOC. It can be concluded that the adjusted model represents accurately the actual battery behavior. The internal resistance plays an important role in the battery voltagecurrent characteristics, especially at the end of the discharge process; these effects are not modeled in this study.

\section{Proposed battery emulator}

The research in energy storage systems, especially those based in batteries, can be costly and difficult because of many different reasons including the reduced battery life due to continuous charge and discharge cycles, costly charging and discharging devices, different results produced by the variation of environmental conditions, required space for battery storage, among others [2], [5]-[7]. A battery-emulator device represents an interesting alternative that, at a reasonable cost, may help overcome most of the aforementioned issues. It brings flexibility in the study of different kinds of batteries, charge and discharge processes may be carried out without degrading the battery life, and parameters like the state of charge, and the dynamic battery behavior can be studied too. The proposed battery emulator is a device capable of behaving like a real lead-acid battery; it is mainly composed of two parts: The charging stage, which consist of a constant current sink that draws current from an external source and updates the SOC to gradually reduce the amount of current drawn from the external source, reproducing the actual response of a lead-acid battery while charging. The discharge stage is based on a DC/DC converter, which dynamically varies the output voltage by adjusting the converter duty cycle according to the current and the battery model response, and therefore the discharge process of a leadacid battery can be simulated under different load conditions.

\subsection{The discharge stage}

The block diagram from Fig. 5 presents the discharge stage of the proposed battery emulator, which can be represented as a current-controlled voltage source since the output current is measured and fed back to the battery model in the control loop whose output is a voltage reference for the power stage.

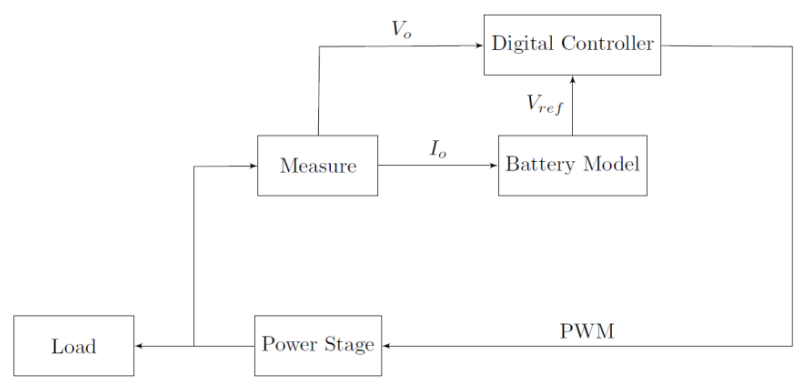

Fig. 5. Block diagram of the discharge stage 
The power stage consists of an off-line flyback converter with an input of $120 \mathrm{~V}-60 \mathrm{~Hz}$. The maximum output power is $100 \mathrm{~W}$. The flyback topology was selected among other galvanically-isolated topologies due to its simplicity and power range [2], [8] and its low cost, since the transformer primary to secondary turns ratio allows to work with relatively large duty cycles [18]. The parameters of the power stage are presented in Tab. 3.

Table 3. Flyback converter parameters

\begin{tabular}{c|c}
\hline Parameter & Value \\
\hline$L(\mu \mathrm{H})$ & 180 \\
$C(\mu \mathrm{F})$ & 3800 \\
$N$ & 3 \\
$f(\mathrm{kHz})$ & 65 \\
\hline
\end{tabular}

In Fig. 6, it is observed that the power stage includes a second filtering stage composed by the choke inductor, in order to attenuate the high-frequency noise from the primary switching stage. In addition, the capacitor $C_{4}$ provides a low impedance path to ground for the high-frequency noise and helps prevent it from reaching the output stage. The line filter located before the diode bridge $D B_{1}$ helps attenuate the highfrequency noise from the switching stage. The snubber circuit $\left(R_{s}, C_{s n}\right.$ and $\left.D_{s n}\right)$ for the high-frequency transformer is essential to ensure the safe operation of the power MOSFET.

The proposed converter is based on a voltage-mode digital controller implemented in the DSP (TMS320F28335) from Texas Instruments. The block diagram of the controller is presented in Fig. 7. The digital implementation of the battery model and the voltage-mode controller allow manipulation of the controller transfer function. Also, some battery model parameters can be dynamically changed to simulate different scenarios, such as full, medium or low charge.

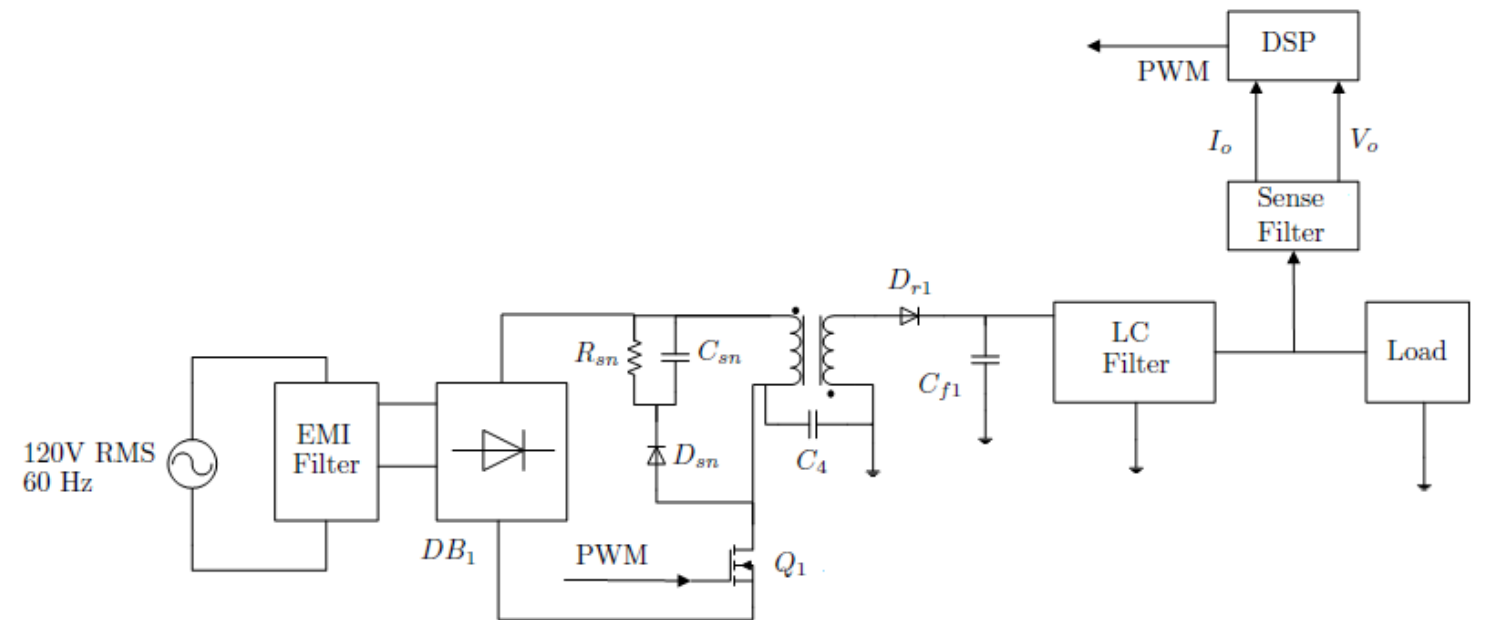

Fig. 6. Simplified circuit diagram of the discharge stage

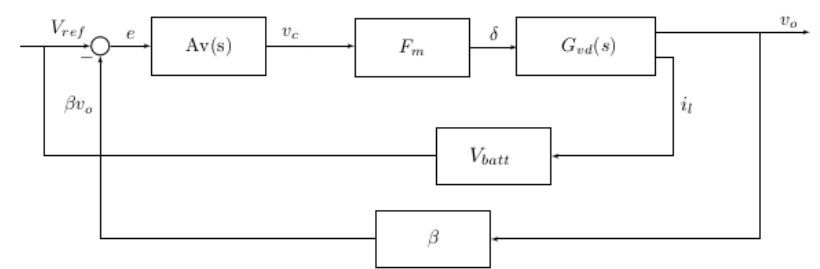

Fig. 7. Block diagram of the proposed control scheme for the discharge stage

In the block diagram presented in Fig. 7 the converter was modeled using the PWM switch technique introduced by Vorpérian et. al [19], $G_{v d}(s)$ is the converter transfer function, which is known as duty cycle to output voltage transfer function. $A_{v}(s)$ represents the transfer function of a compensator type III, $F_{m}$ is the PWM modulator gain, $\beta$ represents the voltage sensing gain, $V_{\text {batt }}$ represents the battery model, which gives the voltage reference.

$G_{v d}(s)$ is described by:

$G_{v d}=G_{d o} \frac{\left(1+\frac{s}{\omega_{Z 1}}\right)\left(1-\frac{s}{\omega_{Z 2}}\right)}{\frac{s^{2}}{\omega_{n}^{2}}+\frac{s}{\omega_{n} Q}+1}$

where $G_{d o}$ is given by:

$G_{d o}=\frac{V_{i}}{N(1-D)^{2}}$
The power stage resonant frequency $\omega_{n}$ is given by:

$\omega_{n}=\frac{1-D}{\sqrt{\frac{L_{m}}{N^{2}} C}}$

The Equivalent Series Resistance (ESR) of the output filter capacitor introduces a zero in the transfer function that is given by:

$\omega_{z 1}=\frac{1}{R_{C} C}$

Additionally, the power stage of the converter has a zero on the complex right-half plane, meaning that this is a nonminimum phase system, this zero is given by:

$\omega_{z 2}=\frac{(1-D)^{2} R}{D \frac{L m}{N^{2}}}$

The quality factor $Q$ is given by:

$Q=\frac{(1-D) R}{\sqrt{\frac{L m}{N^{2}}}}$

$\omega_{z l}$ was chosen to be under the natural resonance frequency of the power stage $\omega_{n}$. $\omega_{p l}$ was chosen carefully so it cancels the zero introduced by the equivalent series resistant of the output filter capacitor. $\omega_{z 2}$ was chosen to cancel the negative phase introduced by the conjugated poles of $G_{v d}(s)$. Finally, 
$\omega_{i}$ was adjusted to reach a phase margin above 50. The parameters of the compensator are summarized in Tab. 4.

Table 4. Type III compensator performance parameters

\begin{tabular}{c|c}
\hline Parameter & Value \\
\hline Phase margin & $50.7^{\circ}$ \\
Gain margin & $14.27 \mathrm{~dB}$ \\
Bandwidth & $3.01 \mathrm{kHz}$ \\
\hline
\end{tabular}

The Bode diagram for the system represented by equation (5) is shown in Fig. 8.

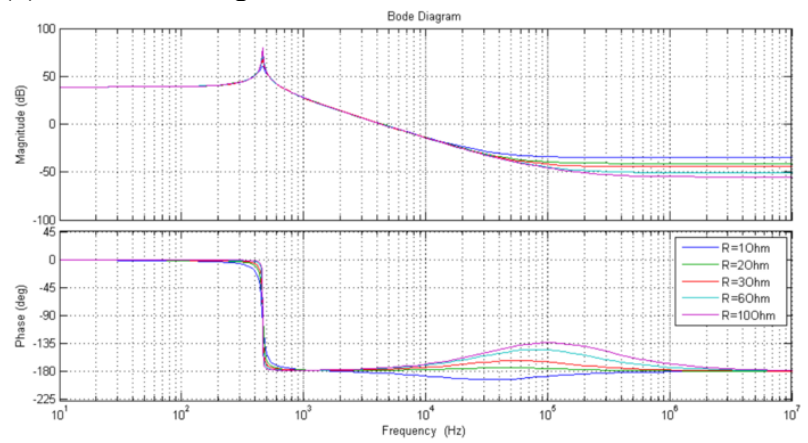

Fig. 8. Bode plot for $G_{v d}(s)$ under different load conditions

It can be seen that at the cut-off frequency of the converter a sharp overshoot may arise, especially under low load conditions. As stated in [19]-[21] the PWM switch model is only valid on Continuous Conduction Mode (CCM). The power stage stays in CCM only for small variations above or below its operating point. If the converter does not operate in $\mathrm{CCM}$, the system may become unstable. Due to this limitation, the battery voltage response under discharge conditions may not be represented with the converter, meaning that very low SOCs cannot be emulated using the proposed battery emulator.

The main components of the control scheme are the gain of the compensator type III, $A_{v}(S)$, and the PWM modulator gain, $F_{m}$. The gain of the compensator type III is given by:
$A_{v}(s)=\frac{\omega_{i}}{s} \frac{\left(1+\frac{s}{\omega_{Z 1}}\right)\left(1-\frac{s}{\omega_{Z 2}}\right)}{\left(1+\frac{s}{\omega_{p 1}}\right)\left(1-\frac{s}{\omega_{p 2}}\right)}$

The gain of the voltage mode control loop is given by:

$T_{v}(s)=A_{v}(s) \cdot F_{m} \cdot G_{v d}(s) \cdot \beta$

The PWM modulator gain and voltage sensing gain parameters are given in Tab. 5.

Table 5. Flyback converter control loop parameters

\begin{tabular}{c|c}
\hline Parameter & Value \\
\hline PWM Modulator Gain & 1 \\
B & 0.1304 \\
\hline
\end{tabular}

The Bode diagram for $A_{v}(S), G_{v d}(S)$ and $T_{v}(S)$ is presented in Fig. 9.

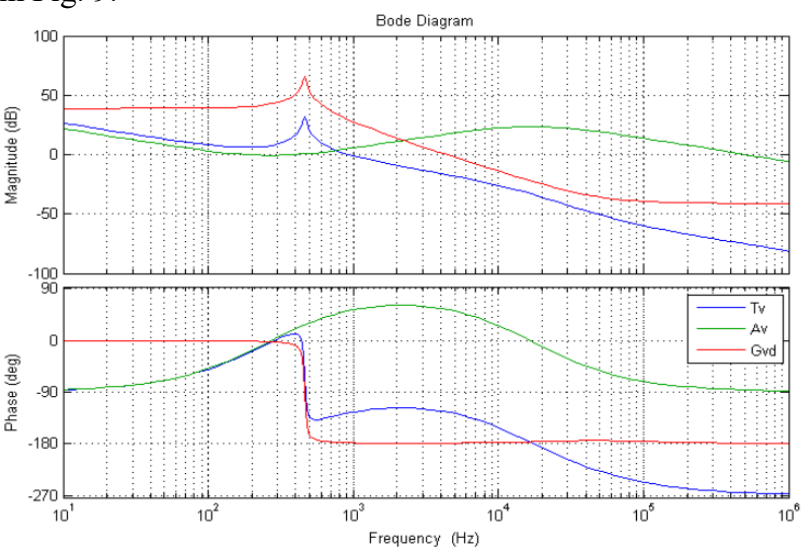

Fig. 9. Bode plot for $A_{v}(s), G_{v d}(s)$ and $T_{v}(s)$

The complete circuit schematic for the discharge stage is presented in Fig. 10.

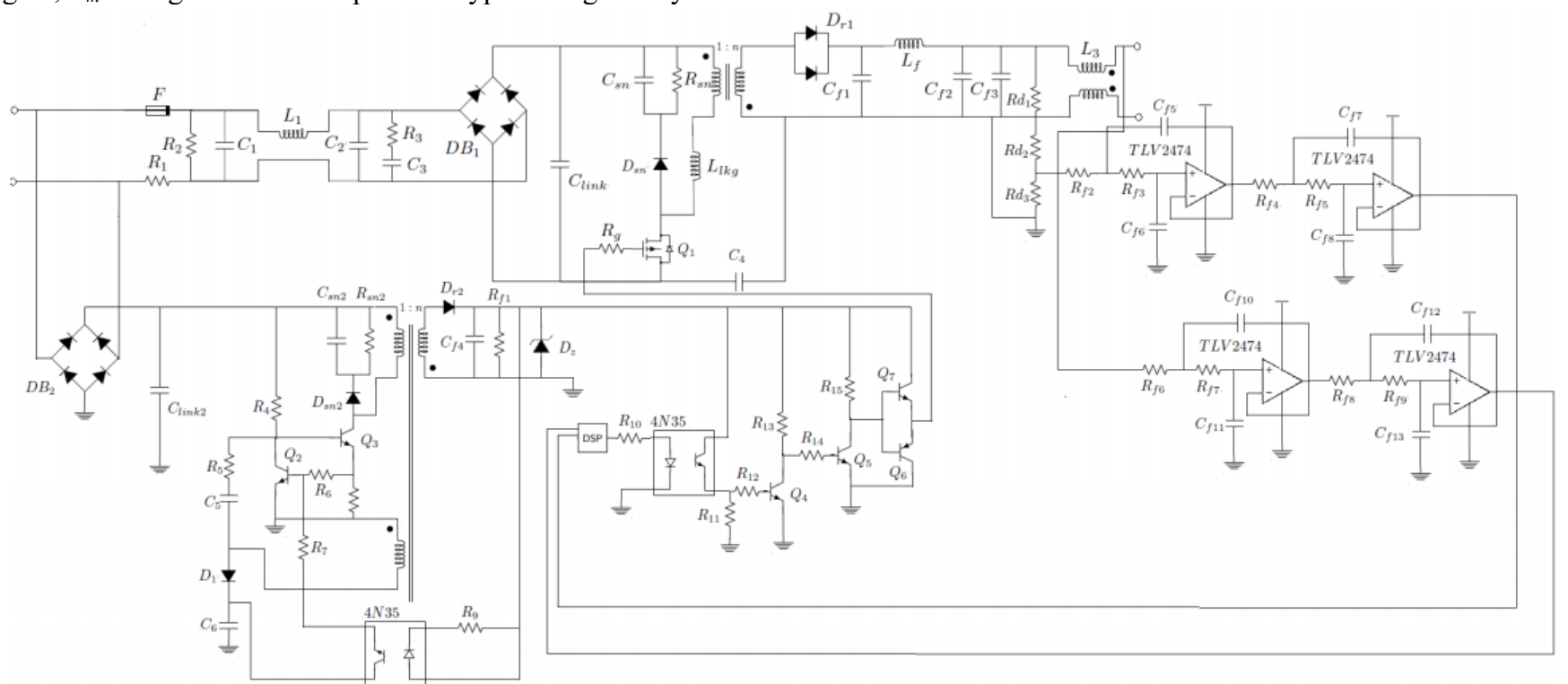

Fig. 10. The complete circuit schematic for the discharge stage

\subsection{The charging stage}

As stated previously, the charging stage is based on a voltagecontrolled constant current sink. When an external charger is connected to the battery emulator, a constant current is drawn from the external charger, the magnitude of the current can be controlled through the Digital Signal Processor depending on the battery SOC, and can be gradually reduced to emulate the final steps of the charging process.

Fig. 11 shows the block diagram of the charge stage, $V e$ and $I e$ are the input variables of the battery model. The current 
charge is determined based on the difference between the voltage on the charger terminal and the internal voltage of the battery model, the latter depending on the SOC. The integration in time of the input current gives the current SOC of the battery. In this way, by means of an equation that stores the previous and the current charge values, the SOC on the battery model is calculated and updated.

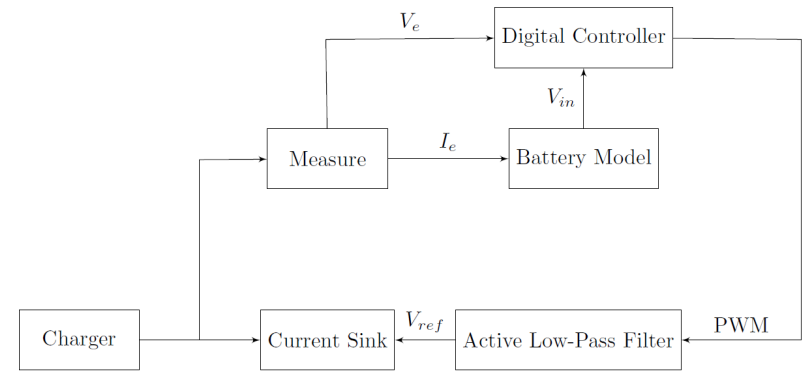

Fig. 11. Block diagram of the charging stage

Fig. 12 presents a simplified circuit diagram of the charge stage. The current drawn from the external charger by the current sink is controlled by a driver and the DSP. An active low-pass filter and a follower amplifier in totem-pole configuration drive a power MOSFET Q. The pulse-widthmodulated signal coming from the DSP is converted into a DC control signal that is applied to the non-inverting input of the follower amplifier. The inverting input of the amplifier is linked to the source of Q1. In this way, the current flowing through a dummy load resistor $\mathrm{R} 1$ is adjusted. By varying the duty cycle of the input signal, the input current changes accordingly to the emulated battery SOC until reaching a full charging state.

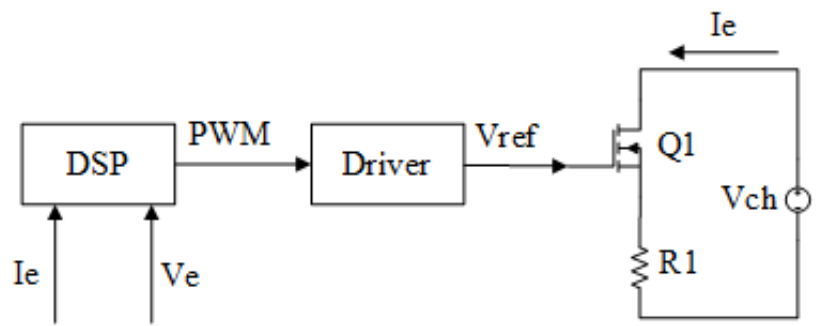

Fig. 12. Simplified circuit diagram of the charge stage

The complete circuit schematic for the charge stage is presented in Fig. 13.

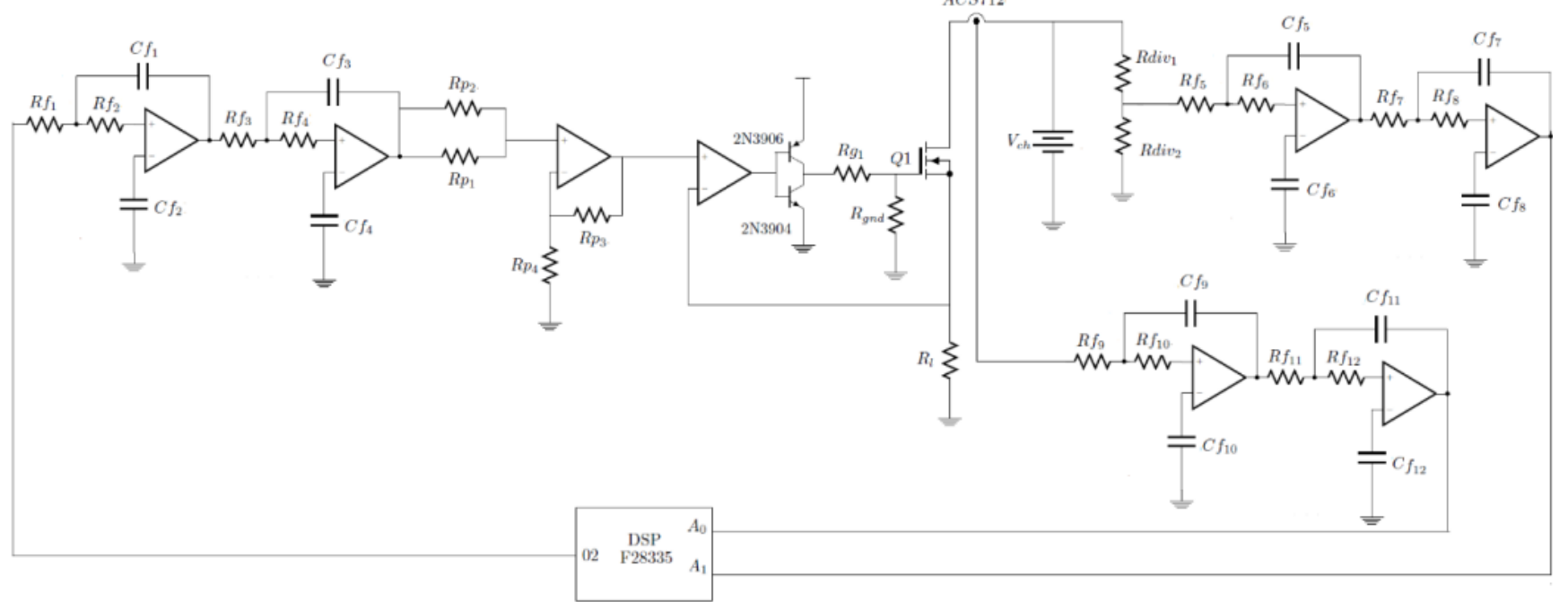

Fig. 13. The complete circuit schematic for the charge stage

\section{Experimental validation of the proposed Battery Emulator}

Fig. 14 shows the experimental set-up built to test the battery emulator.

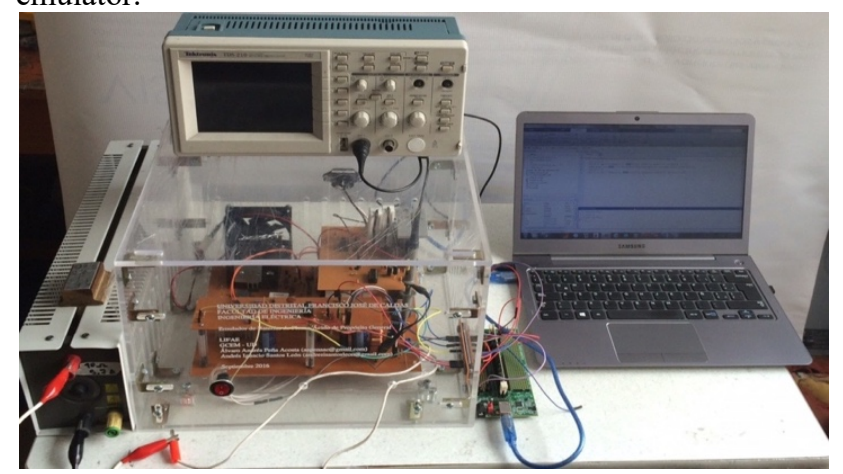

Fig. 14. Experimental Set-Up of the Battery Emulator
Fig. 14 shows the battery emulator. A stage change-over switch was implemented to use the same terminals in the emulator for the charge and discharge stages; this switch is controlled with a digital output from the DSP and the proper code. The current and voltage characteristics of the battery emulator were recorded using the DSP and MATLAB.

Several laboratory tests were performed on the developed prototype to verify its functionality. The pulsed discharge tests previously discussed were reproduced using the battery emulator. In addition, a constant current discharge and charge test was carried out.

The first test corresponded to the pulsed discharge current, in which a $1.2 \mathrm{~A}$ pulse current was applied to the battery emulator during $2500 \mathrm{~s}$. Fig. 15 shows the obtained results from the pulsed discharge test at $1.2 \mathrm{~A}$. 

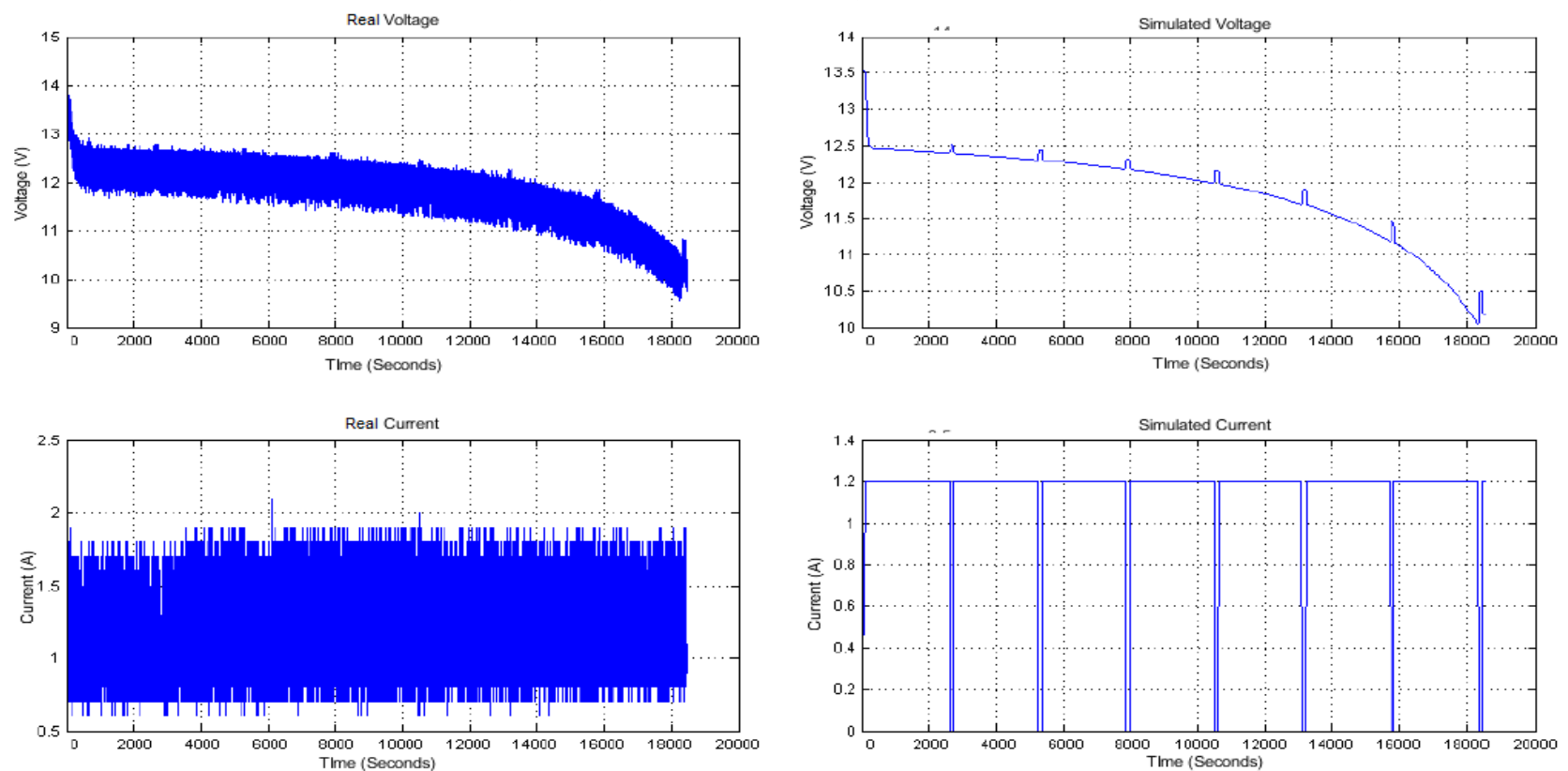

Fig. 15. Real (Left) and Simulated (Right) battery response under a pulsed discharge of $1.2 \mathrm{~A}$

The measuring devices sensitivity and the resolution of the analog inputs of the DSP contributed to the error in the data collected from the experimental tests, especially in the current measurement. These effects were reduced using active filters between the measuring device and the DSP. However, for currents of smaller magnitude, sharp oscillations that do not correspond to the dynamic behavior of the lead-acid battery were obtained.

In the second test, a pulsed discharge current of $3.5 \mathrm{~A}$ was applied to the battery emulator during $2500 \mathrm{~s}$. Fig. 16 shows
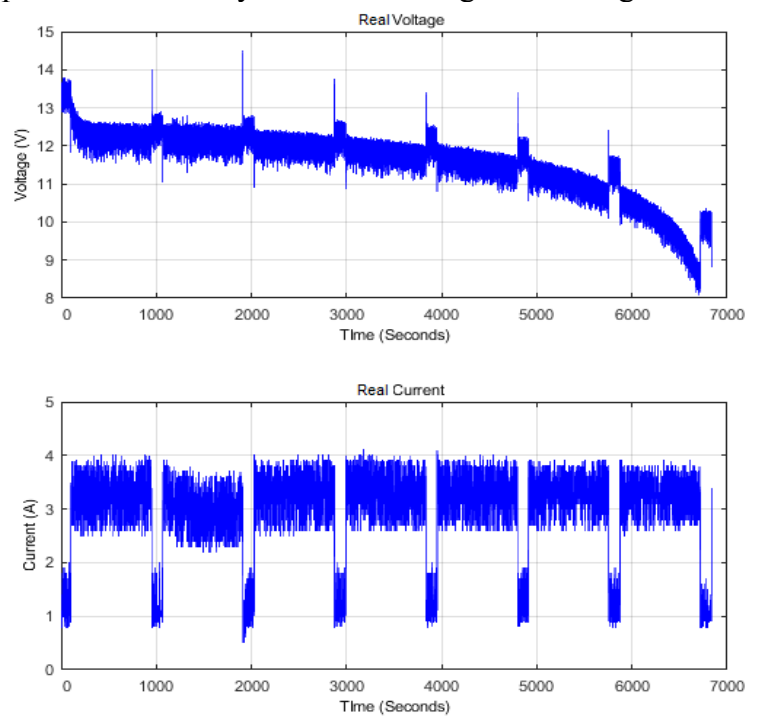

the results of that test. As the input current increases, the emulator reproduces in a better way the behavior of a real battery, this is observed in the voltage and current signals presented in Fig. 16. However, a sharp overshoot is observed at each pulse transition in the converter, this is associated with the transient response of the compensator type III.

Fig. 17 shows a detailed comparison between the real and the simulated voltage. Both signals have the same behavior, except for the oscillations that occur in the real case.
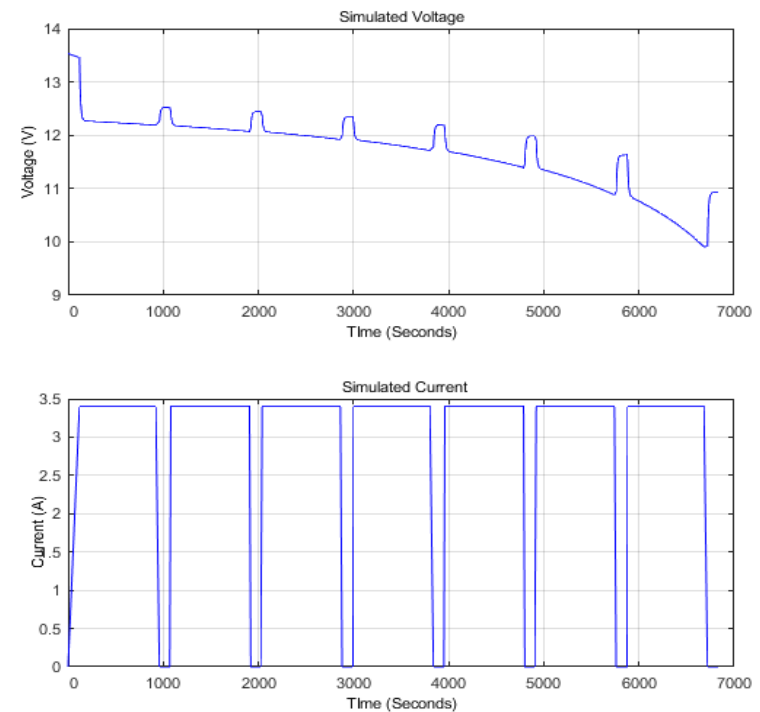

Fig. 16. Real (Left) and Simulated (Right) battery response under a pulsed discharge of $3.5 \mathrm{~A}$

In the next test, the prototype was adjusted to ensure a constant current discharge, in order to verify that it was able to emulate the actual response of a lead-acid battery. In the test, a discharge current of $4 \mathrm{~A}$ was used and the theoretical run-time of the battery was around $1.8 \mathrm{~h}$. During the test, the energy was dissipated for a dummy load resistor. Fig. 18 shows the results obtained from the test. It can be seen that the battery emulator adequately represents the behavior of a real lead-acid battery under a constant current discharge.

To fully verify the functionality of the battery emulator, tests for different SOC levels were performed, in order to observe the battery internal voltage variation to SOC increments. Since the current drawn for external loads is controlled in part by the internal battery voltage, it is expected that the emulator will gradually reduce the charging current and emulate a typical charging process. Initially, a test with a SOC of $50 \%$ was carried out. The results are presented in Figure 19. As can be seen, the battery reaches its full charge voltage after about $3 \mathrm{~h}$.

Next, a new charging process was conducted from a SOC of $20 \%$. The results show that the battery internal voltage increases more rapidly. Fig. 20 shows these results. 
From the results of Figures 19 and 20, it can be seen that the emulator accurately represents the battery internal model and it is capable of adjusting the charging current while increasing the internal voltage.

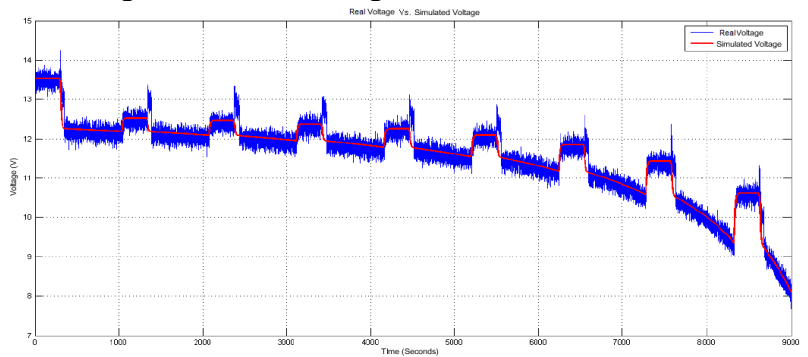

Fig. 17. Real (Blue) and Simulated (Red) Battery Voltage with a pulsed discharge of $3 \mathrm{~A}$

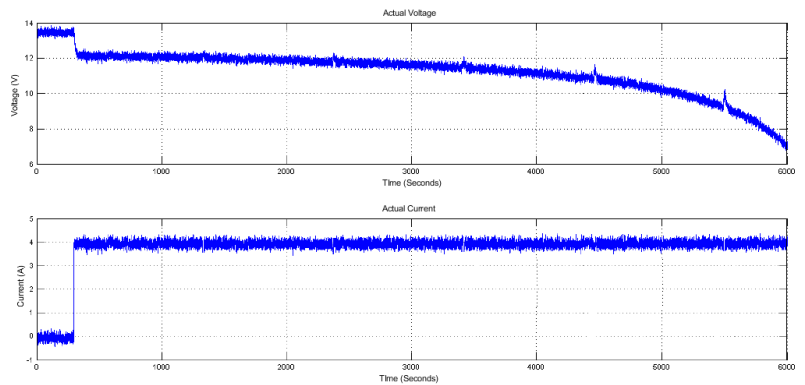

Fig. 18. Results of constant current discharge applied to the proposed Battery Emulator
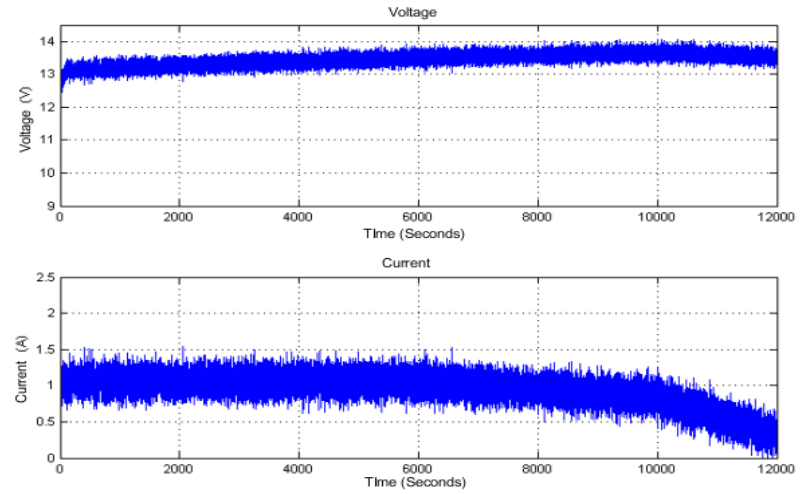

Fig. 19. Results of constant current charge applied to the proposed Battery Emulator with a SOC of $50 \%$

In general, the developed battery emulator accurately represents the lead-acid battery behavior; however, it is not capable of reproducing the full voltage range of lead-acid batteries when the SOC is very low. This is because the PWM switch model used is only valid for CCM. However, the battery emulator can be improved by implementing a secondary digital controller that allows the operation in DCM.

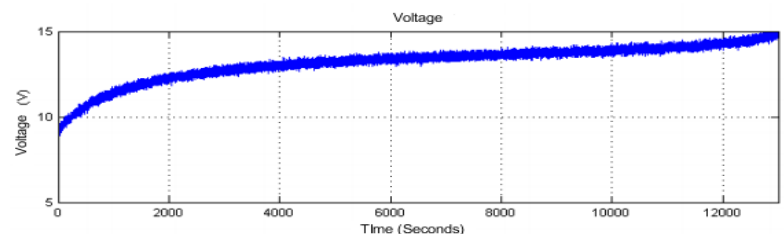

Current

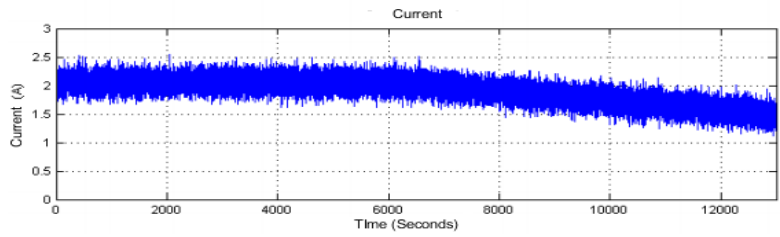

Fig. 20. Results of constant current charge on the proposed Battery Emulator with a SOC of $20 \%$

\section{Conclusion}

In this article, the design and implementation of a lead-acid battery emulator were presented. Through experimental tests, the parameters of the selected battery model were adjusted and its operation validated.

The emulator is based on an Offline Flyback DC/DC converter, for its design, the PWM switch model was used to obtain the continuous-time output-voltage transfer function and to design the voltage mode controller. This model is valid for small-signal analysis and, therefore, imposes a limitation on the validity of the model for small variations above or below the operating point, which in turn limits the emulator operation within a small voltage range.

Comparing the results obtained with the emulator against a real battery, it can be concluded that the former reproduces accurately the dynamic behavior of the battery; however, the transient response of the digital voltage-mode controller may produce a small excess in the voltage response of the emulator in the transition from load to open circuit, which can interfere with the correct operation of the battery emulator.

Despite these limitations, the proposed emulator is a useful tool to be used in typical battery tests, without the degradation of real batteries. It can also be used for the development of battery-based energy storage systems, such as electric vehicles, UPS, distributed generation schemes and renewable energy systems.

\section{Acknowledgments}

This work was sponsored by the national department of science and technology of Colombia COLCIENCIAS, under grant FP44842 - 0312016.

This is an Open Access article distributed under the terms of the Creative Commons Attribution License

\section{References}

[1] O. Tremblay, L. A. Dessaint, and A. I. Dekkiche, "A generic battery model for the dynamic simulation of hybrid electric vehicles," in VPPC 2007 - Proceedings of the 2007 IEEE Vehicle Power and Propulsion Conference, 2007.

[2] S. Thale, R. Wandhare, and V. Agarwal, "A novel low cost portable integrated solar PV, fuel cell and battery emulator with fast tracking algorithm," in 2014 IEEE 40th Photovoltaic Specialist Conference, PVSC 2014, 2014.

[3] O. Tremblay and L. A. Dessaint, "Experimental validation of a battery dynamic model for EV applications," World Electr. Veh. J., 2009.
[4] T. Kim and W. Qiao, "A hybrid battery model capable of capturing dynamic circuit characteristics and nonlinear capacity effects," IEEE Trans. Energy Convers., 2011.

[5] A. Collet, J. C. Crebier, and A. Chureau, "Multi-cell battery emulator for advanced battery management system benchmarking," in Proceedings - ISIE 2011: 2011 IEEE International Symposium on Industrial Electronics, 2011.

[6] T. Baumhofer, W. Waag, and D. U. Sauer, "Specialized battery emulator for automotive electrical systems," in 2010 IEEE Vehicle Power and Propulsion Conference, VPPC 2010, 2010.

[7] C. Park, J. Liu, and P. H. Chou, "B\#: A battery emulator and power- 


\section{Journal of Engineering Science and Technology Review 13 (3) (2020) 172 - 180}

profiling instrument," IEEE Des. Test Comput., 2005.

[8] M. Doyle, "Modeling of Galvanostatic Charge and Discharge of the Lithium/Polymer/Insertion Cell," J. Electrochem. Soc., 1993.

[9] G. L. Bressanini, T. D. C. Busarello, and A. Peres, "Design and implementation of lead-acid battery state-of-health and state-ofcharge measurements," in 14th Brazilian Power Electronics Conference, COBEP 2017, 2018.

[10]H. Keshan, J. Thornburg, and T. S. Ustun, "Comparison of LeadAcid and Lithium Ion Batteries for Stationary Storage in Off-Grid Energy Systems," PowerAfrica 2017 IEEE PES, 2017.

[11]K. Ananda-Rao, R. Ali, S. Taniselass, and N. Baharudin, "Microcontroller based battery controller for peak shaving integrated with Solar Photovoltaic," in 4th IET Clean Energy and Technology Conference (CEAT 2016), 2016.

[12]C. L. Trujillo, D. Velasco, E. Figueres, G. Garcerá, and R. Ortega, "Modeling and control of a push-pull converter for photovoltaic microinverters operating in island mode," Appl. Energy, 2011.

[13] W. L. Jing, C. H. Lai, W. S. H. Wong, and M. L. D. Wong, "Cost analysis of battery-supercapacitor hybrid energy storage system for standalone PV systems," in 4th IET Clean Energy and Technology Conference (CEAT 2016), 2016.

[14]N. Daniil and D. Drury, "Investigation and validation of methods to implement a two-quadrant battery emulator for power Hardware-inthe-Loop Simulation," in IECON Proceedings (Industrial Electronics Conference), 2016.
[15]N. Daniil and D. Drury, "Improving the stability of the battery emulator - Pulsed current load interface in a Power Hardware-in-theLoop Simulation," in IECON Proceedings (Industrial Electronics Conference), 2016.

[16]E. Radu, P. Dorin, P. Toma, and L. Eniko, “An islanded renewable energy microgrid emulator for geothermal, biogas, photovoltaic and lead acid battery storage," in IEEE International Symposium on Industrial Electronics, 2017.

[17]O. Shekoofa, N. Pouryaie, K. Sohrabzadeh, and M. Rezvani, "Improving the EGSE of power subsystem by design and development of a battery emulator for space applications," in RAST 2009 - Proceedings of 4th International Conference on Recent Advances Space Technologies, 2009.

[18] C. L. T. Rodriguez, N. L. D. Aldana, and J. A. H. Mora, "Controller design for a flyback converter, in operating interconnected to grid mode, for photovoltaic applications," Rev. Fac. Ing. Antioquia, 2012.

[19] V. Vorpérian, "Simplified Analysis Of Pwm Converters Using Model Of Pwm Switch Part I: Continuous Conduction Mode," IEEE Trans. Aerosp. Electron. Syst., 1990.

[20] W. M. Moussa and J. E. Morris, "Comparison between state space averaging and PWM switch for switch mode power supply analysis," IEEE Tech. Conf. South. Tier, 1990.

[21]C. C. W. Liu, J. C. R. Lin, M. Chen, C. Chang, W. Liu, and J. Chen, "Modified PWM switch model for continuous conduction mode DCDC converters with coupled inductors," Power Electron. ..., 2010. 